\title{
DE UM RABISCO NO PAPEL PARA O SENTIDO DO LUGAR: O ESTUDO GEOGRÁFICO DE CRIANÇAS COM TRANSTORNO DO ESPECTRO AUTISTA (TEA) NO AMBIENTE ESCOLAR
}

\author{
Leandro Buzzo Mourão Guimarães ${ }^{1}$ \\ Raul Borges Guimarães ${ }^{2}$ \\ Andreia Cristiane Silva Wiezzel ${ }^{3}$
}

\begin{abstract}
Resumo: Transtorno do Espectro Autista (TEA) é uma patologia que apresenta perturbações no desenvolvimento neurológico, tendo como principais características a limitação nas comunicações sociais e nos comportamentos fixos ou repetitivos, afetando crianças geralmente aos dois anos de idade. Tendo em vista essas características, o presente trabalho visa contribuir, do ponto de vista da interlocução entre geografia e psicanálise para a discussão a respeito produção do lugar de crianças com TEA no ambiente escolar. Partindo deste pressuposto, nos utilizamos da técnica do rabisco publicado pelo psicanalista D.W. Winnicott no ano de 1968.
\end{abstract}

Palavras-chave: geografia e psicanálise, técnica do rabisco, lugar

\section{A SCRIBBLE ON A PAPER FOR THE SENSE OF PLACE: THE GEOGRAPHIC STUDY OF CHILDREN WITH AUTISM SPECTRUM DISORDER (ASD) IN THE SCHOOL ENVIRONMENT}

\begin{abstract}
Autistic Spectrum Disorder (ASD) is a pathology that presents neurodevelopmental disorders, it's have principal characteristics like limitation in social communications and in fixed or repetitive behaviors, affecting children generally at two years of age. The present work aims to contribute, considering these characteristics the interlocution between geography and psychoanalysis for the discussion about the production of the place of children with ASD in the school environment. Based on this assumption, we use the scribble drawing developed by the psychoanalyst D.W. Winnicott in 1968.
\end{abstract}

Keywords: geography and psychoanalysis, scribble drawing, place

\footnotetext{
${ }^{1}$ Aluno de pós-graduação em geografia Unesp - Campus de Presidente Prudente -SP. leandro.buzzo.12@eduapps.unesp.br

${ }^{2}$ Professor Associado do departamento de geografia da UNESP - Campus de Presidente PrudenteSP. raul@fctunesp.br

${ }^{3}$ Professora Assistente Doutora do Departamento de Educação na UNESP- Campus de Presidente Prudente-SP. andreia@fctunesp.br
} 


\section{GEOGRAFIA E PSICANÁLISE: UM CAMINHO DE POSSIBILIDADES}

Numa folha qualquer eu desenho um sol amarelo,

$\mathrm{E}$ com cinco ou seis retas é fácil fazer um castelo.

Corro o lápis em torno da mão e me dou uma luva, E se faço chover, com dois riscos tenho um guarda-chuva. Se um pinguinho de tinta cai num pedacinho azul do papel, Num instante imagino uma linda gaivota a voar no céu. Vai voando, contornando a imensa curva Norte e Sul, Vou com ela, viajando, Havai, Pequim ou Istambul.

$[\ldots]$

Nessa estrada não nos cabe conhecer ou ver o que virá.

O fim dela ninguém sabe bem ao certo onde vai dar.

Vamos todos numa linda passarela.

De uma aquarela que um dia, enfim, descolorirá.

Numa folha qualquer eu desenho um sol amarelo (que descolorirá).

E com cinco ou seis retas é fácil fazer um castelo (que descolorirá).

Giro um simples compasso e num círculo eu faço o mundo (que descolorirá).

Aquarela, Toquinho

A partir da subjetividade dos processos psíquicos dos envolvidos nas experiências vividas na escola, no caso crianças com Transtorno do Espectro Autista. Particularmente, nos interessa discutir neste artigo as possibilidades de uso do desenho infantil na compreensão do sentido do lugar a partir de crianças com essa síndrome. A letra da música Aquarela, na epígrafe do texto, evoca dois principais sentidos do lugar experenciados por essas crianças: a transitoriedade e a tenacidade nas relações destes sujeitos.

Para compreensão das discussões levantadas acima, buscamos estudos que conseguissem abarcar os assuntos levantados, mais principalmente, na busca de compreender o ponto de vista dos sujeitos. Assim, buscamos na interdisciplinaridade entre a Geografia e Psicanálise compreender o sentido de lugar com maneiras não tradicionais e que puderam dar respostas que fugissem das perspectivas habituais.

Diante dos fatos, entendemos então, que o foco no estudo do sentido do lugar é a possibilidade de compreensão desse objeto - o espaço geográfico, onde o centro das analises está no sujeito. Pratica-se, assim, não uma geografia dos sujeitos, mas uma geografia para os sujeitos, preocupada com a vida das pessoas onde elas vivem, percebem e elaboram seu próprio entendimento acerca do mundo.

Pensando de maneira incisiva na relação da geografia e psicanálise, e no debate que se coloca, indagamos a seguinte pergunta: Porque estudar os processos referentes à vida psíquica dentro da Geografia? Essa pergunta se faz pertinente porque durante muito tempo esses saberes foram considerados 
além dos limites dos saberem geográficos (PARR; DAVIDSON, 2014), assim como o estudo do corpo e sua corporeidade - como destacado por Alves (2010), e das emoções, a partir de Bondi (1999).

$\mathrm{Na}$ tentativa de responder a questão indagada nos recorremos a Bondi (1999), um geógrafo engajado em estudos sobre feminismo, começou a teorizar em um artigo, com efeito, bastante sentimental, o que poderíamos chamar de uma aproximação entre a psicanálise e a Geografia humana. Por meio de ideias simples, porém, valiosas, conseguiu conectar esses dois campos teóricos, abrindo espaço para o debate acerca das lacunas e as possíveis interlocuções encontradas. Em seus relatos declara que

\begin{abstract}
"Nesta fase, tudo o que posso oferecer é uma sugestão em vez de um argumento exaustivamente aprofundado, mas, no entanto, sugiro que a geografia humana tenha esquecido ou negligenciado as ligações com o movimento de psicoterapia humanista (BONDI, 1999, p.229, tradução nossa)".
\end{abstract}

Os estudos realizados por Bondi (1999) decorrem de duas aproximações teóricas com a geografia, expressas em Freud, as quais seriam os conceitos de transferência ${ }^{4}(1912)$ e de ego ${ }^{5}(1927)$. Apesar de se utilizar de autores pós Freudianos como Lacan, seus estudos mostraram um olhar ainda muito organicista da visão psicanalítica, descrevendo tal campo científico com uma imagem do sujeito descentrado, com impulsos inconscientes, ideias e desejos.

$\mathrm{Na}$ atualidade autores de vários países como Kingsbury, P. (2003, 2009); Sibley, D. (2003); Bingley (2003), A.F; Callard, F.; (2003); Bondi, L (2003,2005,2006); Davidson, J. (2003,2005,2007); Gold, J.R. (2009), dentre muitos outros, têm se debruçado sobre como a teoria sobre a psique que podem servir para conectar o inconsciente, as emoções e o mundo social e material por meio de estudos de medição psicológica em comportamentos espaciais, de geografias emocionais, estudos cognitivos dentre outros trabalhos.

Tamanha importância desta vertente nos estudos geográficos levou, em 2003, a revista Social and Cultural Geography a lançar uma edição (vol.4 ed.3) e, posteriormente, em 2015, o livro Psychoanalytic Geographies, que

\footnotetext{
${ }^{4} \mathrm{O}$ conceito de Transferência. Freud (1912) em seu livro "Técnicas psicanalíticas" teoriza que cada indivíduo, através da ação combinada de sua disposição inata e das influências sofridas durante os primeiros anos, conseguiu um método específico próprio de conduzir-se na vida, e quando o psicanalista volta ao passado do indivíduo para tentar compreender o que aconteceu com sua vida, o paciente se utiliza de emoções, desejos, impressões vividas na infância e expressos na atualidade. É importante ressaltar, de acordo com Buck e Santos (2009), que este processo pode acontecer entre aluno-professor, ou em uma entrevista na pesquisa qualitativa.

${ }^{5}$ Freud (1927) considera que a psiquismo humano é composto do inconsciente e consciente, propondo três conceitos para explicar essa dinâmica: Id, Ego e Superego. O id está ligado ao princípio do prazer, das satisfações mais arcaicas do ser humano. O Ego funciona evitando as dores resultantes da convivência social, serve como um mediador entre o ld e as relações que acontecem no mundo externo, está ligado à realidade, lutando constantemente na tentativa de estabelecer um controle dos instintos que estão no Id. O ego busca, ainda, formas adequadas de realização dos desejos do Id, de maneira a não expor o indivíduo a conflitos emocionais/sociais, que poderiam trazer consequências desastrosas a sua vida. O Superego representa a moralidade, as regras de convivência representados pelos pais por meio da cultura; representa um ego-ideal.
} 
reverberam essa carga de estudos acumulados desde então. Callard (2003), uma das participantes desta edição da revista, relata em seus estudos que as geografias sociais e culturais, principalmente com a virada do século, têm usado autores psicanalíticos como Freud, Lacan, Winnicott, Klein entre outros para o aprofundamento da subjetividade e dos processos psíquicos em analises espaciais.

Feita a contextualização da pesquisa, enfocamos neste presente trabalho a aplicação no estudo geográfico de um procedimento metodológico da Psicanálise de D. W. Winnicott (1968), a qual se denomina Técnica do Rabisco. Essa técninca visa compreender a dimensão dos sujeitos nos lugares vivios de uma maneira lúdica, o detalhamente e compreensão se derá ao longo do texto.

\section{O USO DA TÉCNICA DO RABISCO EM UMA PESQUISA GEOGRÁFICA}

Essa técnica advém da psicanálise desenvolvida por D.W. Winnicott em 1964 e publicada em 1968. Seus escritos sobre o assunto se encontram no livro "Explorações psicanalíticas". Winnicott (1968) salienta em primeira instância que tal técnica serve como uma aproximação, para estabelecer contato com o paciente infantil.

O jogo é composto de duas pessoas, em que qualquer pessoa pode jogar, mas que na vida social o jogo deixa de ter algum significado. Nesse sentido, essa técnica não apresenta regras e regulamento apenas uma mesa com papéis e dois lápis. Posteriormente, rasga-se a folha para parecer que a brincadeira não tem nenhum significado para a criança.

Winnicott (1968), em sequência, salienta a criança que o jogo não tem regras e faz um rabisco perguntando a ela se este é parecido com algo que ela vê ou se ela pode transformá-lo em algo. Depois a brincadeira se inverte, a criança rabisca e o aplicador o transforma em um desenho. O terapeuta contribui com sua engenhosidade no desenho, assim como a criança, porém, seus desenhos tornam-se descartáveis por ser a comunicação/aflição da criança a única que interessa como elemento de análise. Cada desenho provém de uma integração que faz parte da pessoa que o desenha, reverberando uma integração tipicamente obsessiva (WINNICOTT,1968). É importante destacar que esse jogo se apresenta apenas como uma brincadeira para a criança, não se fazendo perguntas que podem desestabilizar e ocasionar traumas.

Mas essa técnica se mostra de extrema relevância para o pesquisador que necessita conhecer mais "a fundo" alguma relação traumática que pode ter ocorrido entre a criança e o lugar, já que Mazzolini (2007) destaca que tal técnica reflete em uma situação, em um Lugar de acontecimentos, ou seja, um Lugar experenciado pela criança.

Para compor a metodologia do trabalho foram utilizadas como instrumentos de coleta de dados, entrevistas com professores e pais de alunos com Transtorno do Espectro Autista e observação participante em sala de aula, 
no sentido de comparação das informações e orientação dos caminhos a serem seguidos durante a aplicação da Técnica do Rabisco, no sentido de captar aspectos importantes não destacados do discurso, pois as entrevistas são dotadas de pessoas que falam aquilo que elas querem falar. Isso não significa uma hierarquização na pesquisa, mas sim apenas um destaque para a Técnica do Rabisco neste trabalho.

Neste âmbito, evidenciamos a pesquisa qualitativa em associação à Técnica do Rabisco, de origem psicanalítica, na composição de uma metodologia geral, elementos que ofereceram contribuição/complementação a uma análise interdisciplinar. A aplicação da Técnica do Rabisco se deu na sala de aula, que possuía 28 alunos, dos quais gostaríamos de destacar apenas dois (Joca e Pedro - nomes fictícios tratados na pesquisa, alunos com Transtorno do Espectro Autista, de acordo com o comitê de ética em pesquisa, n.55005416.2.0000.5402).). A técnica desenvolvida por Winnicott (1968) é aplicada em um lugar em que apenas há a presença de quem está aplicando e a de quem está sendo aplicado, porém, como estamos trabalhando dentro de um processo de inclusão escolar, aplicar tal técnica de maneira individualizada poderia resultar numa situação de segregação entre os alunos com TEA e os outros alunos presentes na sala de aula, já que haveria comunicação entre eles.

O processo ocorreu no início da aula, com a ajuda da professora titular da turma e uma tutora que acompanha desde o começo do ano o Joca, pela sua maior limitação mental. O primeiro passo foi juntar as carteiras em duplas para que os próprios alunos fizessem a brincadeira, um rabiscando e o outro desenhando e depois os papéis se invertiam. Winnicott (1968) relata que essa técnica pode ser utilizada como um jogo para as crianças, mas que não teriam valor científico para o trabalho.

Porém, isto não poderia ocorrer da mesma forma com as crianças com TEA, já que seus desenhos seriam analisados posteriormente. Então, o pesquisador passou as orientações da técnica para a tutora de Joca e solicitou que fizesse par com ele. O pesquisador escolheu a tutora e não a professora para que ficasse com Joca devido à maior proximidade entre eles, podendo ajudar com maior facilidade caso houvesse alguma dúvida.

O pesquisador se sentou ao lado de Pedro e bem perto da carteira da tutora, pois, enquanto fazia a atividade com Pedro, poderia também orientar a tutora caso houvesse algum questionamento. $O$ pesquisador se sentiu confortável sentando-se ao lado de Pedro e percebeu o mesmo por parte do garoto, já que haviam criado laços

afetivos durante a presença do primeiro em sala de aula quatro meses antes, devido à observação participante.

A professora assumiu o papel de explicar à sala de aula como se daria a "brincadeira" e ajudar no desenvolvimento desta enquanto o pesquisador e a tutora aplicavam a técnica com os alunos com TEA. Vários alunos vieram nos mostrar o que haviam desenhado e ficaram muito contentes com a "brincadeira". A aplicação da técnica ocorreu de forma satisfatória junto aos alunos com TEA. 


\section{A PRODUÇÃO DO LUGAR A PARTIR DE CRIANÇAS COM TRANSTORNO DO ESPECTRO AUTISTA}

Winnicott (1990), além de todo seu tratamento metodológico ainda nos vem ajudar a refletir sobre o ponto de vista geográfico. Em em seu trabalho sobre a natureza humana, ressalta a relação simbólica com o ambiente desde o nascimento, onde o primeiro lugar para a criança é colo da mãe e, a partir de cuidados cotidianos a criança adquire aspectos sociais e culturais que a possibilitam conviver no espaço geográfico.

Os lugares, portanto, só podem ser produzidos por quem vive neles na forma conjunta de construções (físicas), atividades e significados. O lugar se estende às ligações inextricáveis com o ser (RELPH, 2012). Assim, o ele transcende à materialidade, mas não está dissociado desta, visto que as marcas e formas espaciais não estão encabeçadas apenas em elementos físicos dos objetos (MELO 2012).

O lugar sempre foi à essência propriamente dita da ciência geográfica, de acordo com a perspectiva Humanista. "Refletir sobre o lugar é refletir o sentido na Geografia (OLIVEIRA, 2012, p.23)". O lugar é pensado nesta visão como uma relação de pertencimento, é o lugar experenciado como aconchego que levamos dentro de nós (OLIVEIRA, 2012.)

Se tomarmos o Espelho como objeto de exemplificação, podemos compreender que nós - seres humanos - somos compostos de aparência e essência, mas ao olharmos nosso reflexo e nos vermos ao espelho, a nossa aparência é refletida, mas a nossa essência não. Assim, nós nos estabelecemos com os lugares, com a essência e, quando isso não é transmitido aos lugares, passamos a construir não lugares, os quais são inóspitos, sem identidades, não passa das aparências.

Contudo, para que esta relação ocorra, a relação simbólica do sujeito com o lugar, Winnicott (1990) salienta que esse cuidado seja suficientemente bom, ou seja, que haja um mínimo cuidado para acontecer uma integração, em que se perceba uma realidade interna diferente de uma realidade externa, na qual o bebe comece a se preocupar com ele e com o outro, não sendo impulsionado pelos aspectos mais orgânicos como os instintos, isto é, que seja uma somatória de estados tranquilos e excitados.

Essa experiência entre ele e uma espacialidade, quando acontece de uma maneira suficientemente boa, possibilita a criação de um verdadeiro self $f^{6}$. Contudo, até chegar a esse estado de integração há falha nesse processo - já que o ambiente nunca consegue acolher o indivíduo de forma ideal - e essa falha causa um estado de repressão da criança.

É importante salientar que Winnicott $(1982,1983,1990)$ propõe uma teoria diferente da qual é expressa por Freud acerca da teoria do consciente e inconsciente. Winnicott (1982) considera que quando há uma sustentação do ambiente, a criança deixa os aspectos instintivos para adquirir os aspectos

\footnotetext{
${ }^{6}$ Winnicott em seu trabalho considera que há dois tipos de transtornos mentais, o primeiro seria a neurose, que tendo o indivíduo chegado à integração psíquica vive reflexos do seu passado, em uma questão identificatória. Já os psicóticos são pessoas que não conseguiram chegar à fase de integração psíquica.
} 
sociais, em que no inconsciente fica apenas uma repressão dos aspectos sociais vividos.

Já na visão de Freud (1927) o consciente é apenas uma "capa protetora", uma fina película criada através das regras sociais/culturais que tenta moldar a realidade dos instintos que continuam existindo nos seres humanos.

Por outro lado, Winnicott (1990) salienta que quando essas falhas ambientais passam a ser constante, a criança deixa de progredir mentalmente, ocorrendo um processo chamado de falso self, em que um estado extremo pode se implantar como um estado real para a criança, como um movimento de defesa. Assim, se o falso self acaba se tornando organizado, criando cada vez novas defesas contra o ambiente, resulta em crianças com Transtorno do Espectro Autista, que na maioria das vezes se tornam psicóticas.

O termo psicose utilizado por Winnicott (1990) corresponde a uma não formação completa do psiquismo humano quando, em condições que ainda não foram alcançadas a diferenciação do Eu e não-EU, as estruturas psíquicas não foram formadas corretamente. Esse processo quase de colapso, dificulta muito o relacionamento estável com os ambientes espaciais que o sujeito vive, pois, em alguns momentos, em que ele nega a espacialidade e sua relação com tal, ele está negando a si mesmo. Essa negação do um determinado ambiente vai gerando novos fluxos negativos que acabam atingindo outros espaços, que criam novas de defesa com o meio externo.

Em vista do exposto acima, fica evidente que o estudo na psicanálise é fundamental para a Geografia, pois o lugar deixa marcas (sejam elas boas ou ruins) nos sujeitos, assim como os sujeitos deixam as suas marcas nos lugares, pois é onde ocorrem relações mais intensas do sujeito e fazem com que criem relações únicas, mesmo elas podendo ser frágeis, transitórias e tenazes, como é o caso de pessoas com transtornos mentais.

Portanto, entendemos que a relação do sujeito com lugar é dada por diferentes fatores. Quando estas relações introjetam e se mesclam no psiquismo humano, produzem uma maneira única do indivíduo se relacionar com o mundo (Silva, 1991). Essas relações vão estabelecendo fluxos subjetivos e participam ativamente da construção de novos lugares.

Isto fica evidente nos dois estudos de casos em que sucederam de um conjunto de traumas que afetaram e afetam as relações com os lugares destes sujeitos. Portanto, para se pensar em uma construção social da categoria lugar, formulamos um conceito pensado a partir da necessidade estudos com sujeitos com algum tipo de transtorno, que tinham dificuldade de se estabelecer com o lugar são relações mais tenazes, com ligações mais fracas, porém existentes. Neste sentido destacamos os lugares pivotantes e os lugares fasciculados.

O termo acima se baseou na premissa de dois tipos de raízes principais, sendo estas pivotantes, a qual existe uma raiz principal que penetra verticalmente no solo, sendo, geralmente, maior e mais espessa e com raízes secundárias que partem dela e auxiliam na fixação. Já, as fasciculadas são formadas por um conjunto de raízes 
finas, todas mais ou menos do mesmo tamanho e espessura, em que não tem uma profundidade tão grande ao solo, ficando nas camadas mais superficiais.

Desta mesma, podemos aplicar estas relações para a construção dos sujeitos com os lugares. Nos lugares pivotantes apesar das relações possuírem alguns traumas, isto não chega a interferir concisamente na construção de lugares solidos. Todavia, não podemos afirmar isto para os lugares fasciculados, onde essas raízes podem ser facilmente rompidas por algum outro fator que se seja mais forte que a ligação com o lugar. Há neste sentido uma tentativa constantemente se fixar substrato, ou seja, no lugar, para manter vínculos, mas que se tornam muito frágeis e facilmente se ser rompidas.

Podemos relacionar os lugares fasciculados a estes dois sujeitos no estudo da pesquisa, as quais devidas acontecimentos hostis durante a sua constituição enquanto do ser construíram lugares facilmente de serem rompidos, destacados no exemplo de Pedro e Joca nos relatos a seguir.

\section{A PRODUÇÃO DO LUGAR DE PEDRO}

Os primeiros rabiscos que analisaremos correspondem à história de vida de Pedro, uma criança com TEA estudante regular da escola municipal de Presidente Prudente-SP. A partir do rabisco do pesquisador, Pedro desenhou um pato sozinho na Lagoa. Esta imagem refletiu nas observações participantes em sala de aula, em que o aluno relatava constantemente que ninguém gostava dele, que seus colegas o estavam falando palavras de baixo calão, que ele queria se matar porque ele era o problema.

Figura 1 - Pato na Lagoa

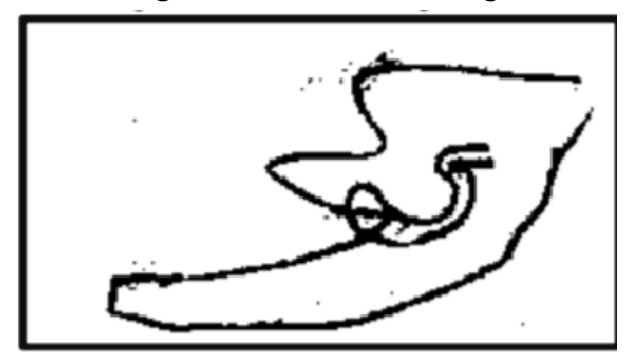

Fonte: Pedro

Prosseguindo com a brincadeira, o pesquisador fez outro rabisco e o desenho resultante foi outro pato, só que dessa vez, o pato e sua mãe estavam virados de costas um para o outro. Durante o desenho, Pedro relatou que era ele e sua mãe. Esse desenho se mostrou muito pertinente, pelo caso específico que Pedro passou em sua trajetória de vida. Segundo entrevista com a avó, a gravidez de Pedro foi complicada e a mãe nunca conseguiu acolhê-lo: não gostava de dar banho, dava pouquíssima atenção, não tinha paciência. A avó relatou os seguintes aspectos:

"A história da mãe e do pai, o pai a gente não sabe quem porque ela... [mãe do Pedro], não tem quem faça ela falar quem é o pai, agora, a mãe, quando ela estava morando aqui 
com a gente, ela e o João, não se dava, e ela não foi uma mãe.... carinhosa com ele, isso ela não foi [indicação de certeza], ela não dava atenção pra ele, ela brigava mais do que dava atenção, a atenção era muito pouca mesmo".

Figura 2 - Pata e seu Filhote na Lagoa

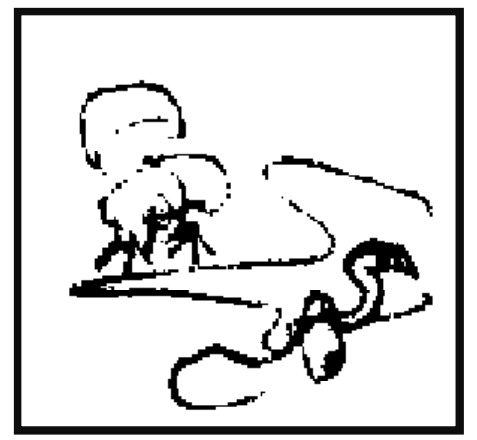

Fonte: Pedro

Pedro começou a frequentar a escola com um ano e cinco meses e teve adaptação muito difícil, chorava, tinha febre. Durante as atividades escolares a mãe fazia as lições ao invés de auxiliar Pedro. Diante de todo o exposto a avó solicitou a guarda do garoto. Desde muito cedo Pedro se sente isolado pelas outras pessoas, principalmente pela mãe.

Os sintomas dessa doença apareceram claramente aos quatro anos e piorou com a ida da mãe para Dubai, Emirados Árabes, em que ainda bem pequeno já apresentava movimento estereotipado com a cabeça e problemas de visão. Esse abandono se projeta na sua construção do lugar, em que apresenta bastante dificuldade em estabelecer relações de pertencimento. Sente que pode ser abandonado novamente, transpondo experiências do seu passado para o seu presente como um movimento de defesa em um constante ataque do falso self para encobrir o verdadeiro self, pois ocultando o verdadeiro self, se oculta a sua realidade. Ainda segundos relatos da Avó;

Ele balançava a cabeça, tanto é que ele foi... [pausa]. Quando eu levei ele no oftalmo, ele passou por um especialista, ah.... a médica fez vários testes nele e que ele tinha problema de visão, daí a especialista falou: - olha se o teste do olhinho se tivesse sido feito, como tem que ser feito no hospital, o João já sairia de óculos. Mas é... esse problema do autismo dele, quem começou a desconfiar que ele tinha autismo foi a psicóloga, lá do... doutora Ana. Aí ela encaminhou pro Neuro Dr. Armenio, ah... a neuro que eu levei ele antes, ela também suspeitava, ela não tinha certeza, ela passou as medicação, mas era suspeita, quem confirmou o autismo dele foi o Dr. Armênio."

Os próximos desenhos feitos pelo Pedro nos ajudaram a compreender melhor seu contexto social atual: um desenho representando um pássaro que, quando tentava voar, sempre era impossibilitado por uma tempestade e constantes raios que o atingiam e outro representando um "pássaro-robô". Ao 
analisar este desenho percebe-se que Pedro é representado pelo pássaro, ou seja, ele tentava crescer, se desenvolver, só que sempre acontecia algo que atrapalhava.

Figura 3 - Avião voando com raios

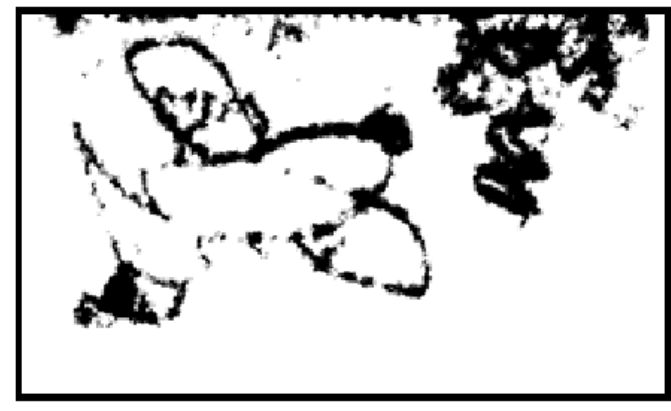

Fonte: Pedro

O desenho presente na figura 4 complementa o anterior, a qual segundo relato de Pedro, representa uma pessoa que criou um "dinossauro-robô" e que esse dinossauro tinha como objetivo levar uma carta. O aluno não revelou o conteúdo da carta ao pesquisador. Ao mostrar o desenho para a professora ela comentou que Pedro só se comunicava com sua mãe através de cartas, pois ela reside no exterior. Neste sentido o desenho relata a necessidade de Pedro se comunicar com a mãe.

Figura 4 - Dinossauro robô

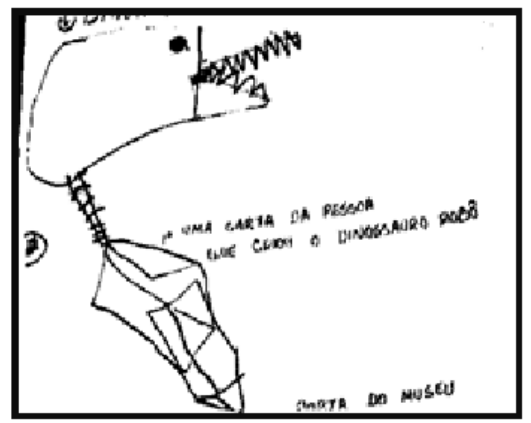

Fonte: Pedro

Após análises concluímos que como o menino não consegue continuar se desenvolvendo cria um falso self, que se manifesta primeiro por um pássaro que tenta seguir viagem e é impedido pela tempestade e que, posteriormente, reaparece transformado em algo mais forte, um "dinossauro-robô", já que o pássaro não foi suficiente para ocultar suas dificuldades. Neste sentido o robô se mostra mais resistente, já que construído com material mais rígido aos impactos, além do seu enorme tamanho, com grandes dentes.

Porém, é digno de nota que o dinossauro apresenta problemas de estrutura física: parece meio desproporcional, faltando partes (falta da integração), não tem um corpo muito definido, os "braços" meio que junto ou fundido ao corpo (como algo não muito bem desenvolvido) e não aparecem as "pernas". Esse menino transvestido de "robô- dinossauro" também demonstra agressividade por meio de sua mandíbula, em um corpo meio fragilizado. 
Na próxima (figura 5 - Porta do Museu), Pedro mostrou quase que um colapso do seu psiquismo, relatando que "a porta do museu estava fechada", além de outro desenho que representa "uma bomba e que ela estava no 99, a um instante de explodir e, de repente a bomba explodiu". Podemos ver claramente um pedido de ajuda já que a bomba que existe dentro dele explodiu, está cansando de tentar voar e cair repetitivamente, se reverberando inclusive em vontade de acabar com a própria vida, como ele comenta no ambiente escolar. É importante mencionar, nesse contexto, que o garoto está sendo acompanhado por um profissional.

Figura 5 - Porta do Museu

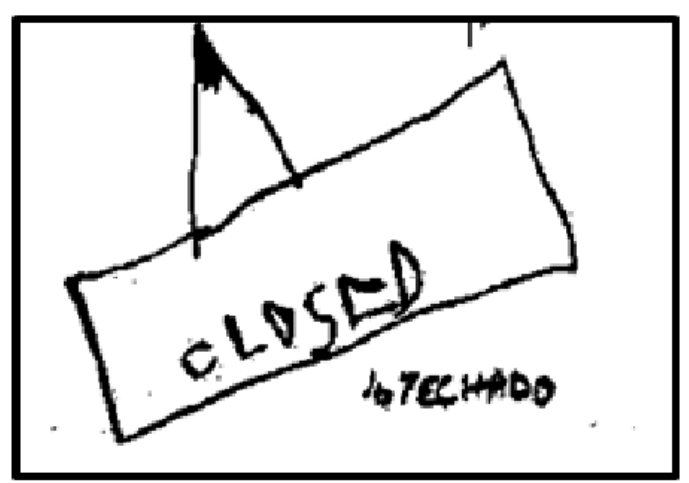

Fonte: Pedro
Figura 6 - Bomba

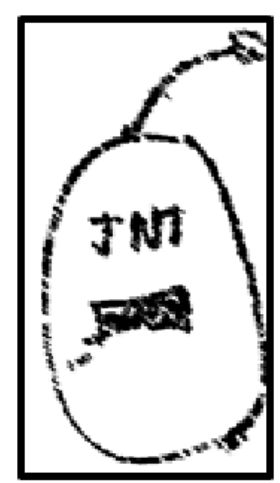

Fonte: Pedro

\section{A PRODUÇÃO DO LUGAR DE JOCA}

O caso de Joca se tornou muito complicado para a análise devido a outros fatores agravantes, como um retardo mental, além do Transtorno do Espectro Autista. Assim, um primeiro resultado que pode ser apontado é o de que o Jogo do Rabisco não se mostra tão interessante com pessoas com grandes transtornos mentais, tendo em vista as possíveis falhas na imaginação e capacidade simbólica (TAMANAHA, 2006).

Ainda assim, quando há a presença de alguém que realiza uma atividade dirigida, como no caso do Jogo de Rabisco, é possível certa exploração da atividade, mesmo que ocorra a partir da imitação do ato do pesquisador, que, no caso, desenha. Desta maneira, apesar de poucas formas e caracterização conseguimos realizar algumas interpretações nos desenhos de Joca, destacando-se, nessa conjuntura, quatro desenhos.

Os desenhos, em geral, são precários pelo comprometimento causado pela síndrome associado à sua limitação intelectual. As dificuldades com representação simbólica e criatividade deixaram os desenhos quase sem formas, ou mesmo faltando partes, mas a partir das verbalizações do garoto e 
características específicas de seus desenhos, foi possível conhecer um pouco mais a respeito dele.

A partir dos relatos, observação participante e entrevista, podemos compreender que Joca vive com seus avôs, e sua mãe mora em uma casa ao lado. Além dos cuidados com os netos, os avôs ainda ajudam de outra neta que vive em estado vegetativo. Joca, em seus desenhos (figura sete e oito), houve a predominância do tubarão. Primeiro apenas a boca aberta, com alguns dentes, com a ausência de várias partes do rosto e ausência total do corpo. Posteriormente representou o tubarão apenas por meio do corpo, sem junta-lo a cabeça. Isso mostra como as coisas se passam dentro dele, a falta de conexões, de integração, seja do ponto de vista cognitivo, seja do ponto de vista emocional.

Figura 7 - Tubarão

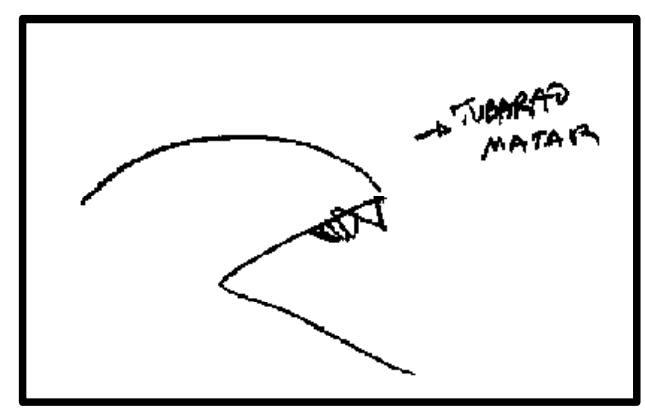

Fonte: Joca
Figura 8 - Tubarão

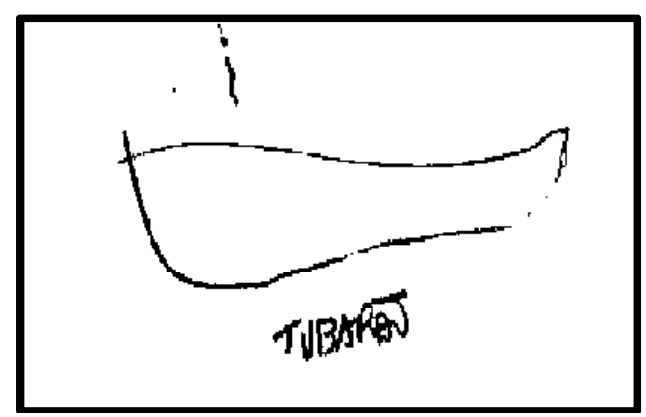

Fonte: Joca

Já quando representa o dinossauro (figura 9), consegue ir um pouco mais além, de forma a fazer um contorno do animal, incluindo a cabeça, ainda que sem os detalhes do rosto. O tubarão, conforme destaque dado a sua mandíbula, com alguns dentes bem pontiagudos, remete a questão da agressividade, de forma bem primitiva e desarticulada do resto do corpo. Por alguns momentos, provavelmente, essa é a forma como ele se vê. Por força de mediação do pesquisador, da empatia e oferecimento de situação propicia a expressão, os desenhos vão evoluindo, de forma que o dinossauro ganha um corpo.

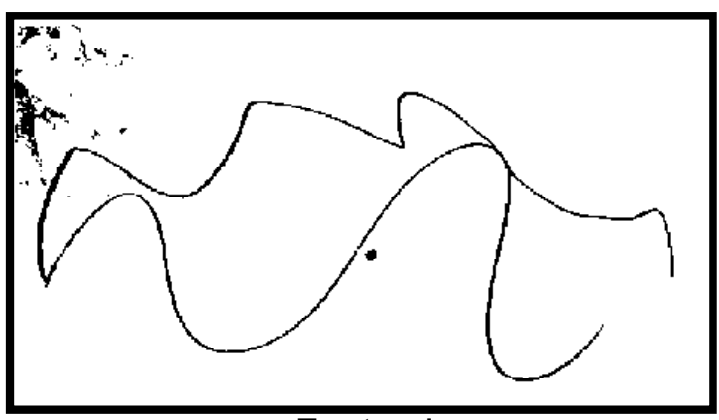

Fonte: Joca 
A figura 11 representa um "ser humano cercado por animais, com muitos gorilas e macacos", conforme Joca. Nota-se, nesse contexto a questão da solidão, muito embora haja a presença de animais. Como o ser humano apresenta-se "cercado" por animais é plausível a existência do medo no contato nas pessoas. Conforme a professora relatou, há dificuldades na interação entre Joca e Pedro, sobretudo quando um dos dois não está muito bem. Apresentam um nervosismo que os levam a agressividade entre si.

Figura 10 - Ilha com gorilas e macacos

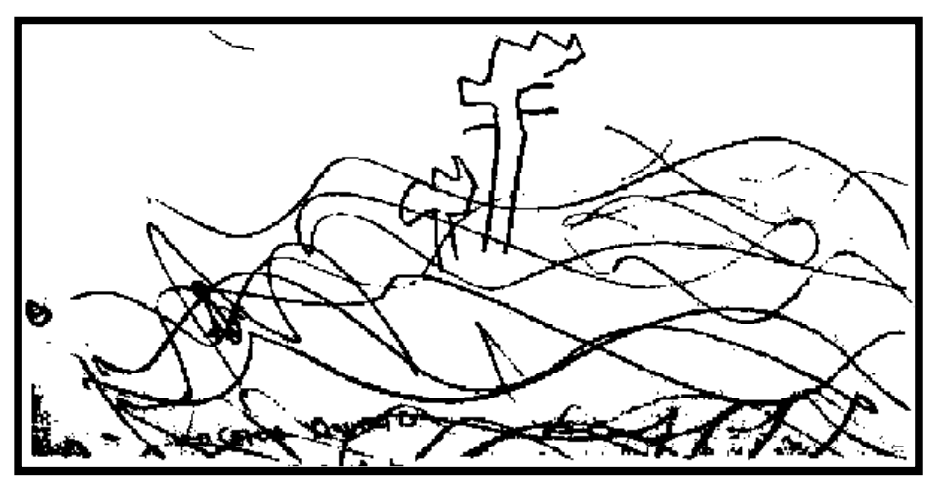

Fonte: Joca

Como já citado, historicamente, Joca não está muito acostumado a convivência. Em casa, até o momento em que fora a escola, teve contatos muito restritos e possivelmente geradores de muita angústia. Para ele, qualquer ambiente, em potencial, representa perigo. Ele se vê muito pequeno, dentro de um emaranhado, meio perdido, "sem chão", assim como mostra no desenho.

$\mathrm{Na}$ escola, inicialmente, era bem agitado, agressivo, mas isso mudou um pouco devido a adequação da medicação, segundo a professora. Assim como Pedro, Joca tem resistência em fazer as atividades e quando "explode" bate nas crianças. Principalmente devido a agressividade, tem uma tutora, que o acompanha no horário escolar. O garoto tem dificuldades de socialização e "implica" com Pedro, ficando a situação muito complicada quando os dois se desentendem, já que são "imprevisíveis", conforme apontou a professora.

A família, devido a situação em que se encontra, não consegue investir no processo de socialização dele, o garoto "não tem vida social, não tem vizinhos e em casa a única atividade consiste em jogar videogame." Diante das dificuldades extremas, ainda que a professora possua especialização em Educação Especial, solicitou auxílio aos gestores escolares, de forma a conseguir um espaço nas reuniões escolares para expor a situação e juntos elaborarem atividades para ele, com auxílio do professor da sala de recursos. A professora mostrou-se muito cansada, frustrada e esgotada diante de tal situação. 


\section{CONCLUSÃO}

Destacamos, em uma análise geral que as duas crianças estudadas tiveram uma relação traumática no início da infância, o que dificultou o estabelecimento de uma relação de pertencimento com o lugar, se reverberando em constantes brigas e sentimento de exclusão. Entretanto, aspectos de verdadeiro self vêm sendo oferecidos a estes sujeitos como constante tentativa de alguns profissionais da escola, principalmente da professora, em encontrar metodologias e maneiras de lidar com essas crianças além da aceitação destas pelos outros alunos, que interagem, brincam e buscam ajudá-los de alguma forma.

Contudo, por mais que a escola se esforce (ainda que com suas falhas), os garotos criaram um sistema de defesa tão forte contra a frustração nos relacionamentos que não se permitem viver bem na escola, de forma que não conseguem crescer nos conflitos que possuem com as outras crianças, mesmo com a mediação dos professores, que nem sempre parece ser a mais adequada, conforme citação da avó de Pedro. Eles acreditam que não merecem amor, têm dificuldades em receber amor por medo de fragilizarem as defesas que criaram para se protegerem.

Apesar de que para essas crianças a relação com lugar ainda possua um elo muito frágil, quando construído de maneira congruente e sólida, pode ajudar imensamente nesse movimento de busca pelo seu verdadeiro eu e na possibilidade da construção de uma relação com outros lugares a partir de fluxos subjetivos.

É importante, nesse sentido, que o lugar para essas crianças seja concebido como sinônimo de cuidado, através de práticas de promoção da saúde que possam oferecer uma sustentação a elas, de modo a acolhê-las psiquicamente de modo suficientemente bom. Que a criança possa amar e odiar, para que possa viver a culpa e a restituição, que se relacione com pessoas que possam sobreviver às suas retaliações e agressividade com possibilidade de reparação sem riscos de rompimento de vínculos e, por fim, alguém que se responsabilize pelo seu cuidado (GUIMARÃES; LUZ, 2015).

\section{REFERÊNCIAS BIBLIOGRÁFICAS}

ALVES, N. C. A cidade inscrita no meu corpo: gênero e saúde em Presidente Prudente-SP. Dissertação (Mestrado em Geografia). Faculdade de Ciência e Tecnólogia, UNESP, Presidente Prudente. 2010.

BINGLEY, A.F. In here and out there: sensations between self and landscape. Social and Cultural Geography, vol. 4(3), 2003.p. 329-45.

BONDI, Liz. Stages on Journeys: Some Remarks about Human Geography and Psychotherapeutic Practice, The Professional Geographer. vol. 51:1. 1999. p.11-24 
. Empathy and identification: conceptual resources for feminist fieldwork. ACME: International Journal of Critical Geography , vol 2, 2003. p. 64-76.

. The place of emotions in research: from partitioning emotion and reason to the emotional dynamics of research relationships. In: Emotional Geographies, J. Davidson, L. Bondi and M. Smith. Aldershot: Ashgate (org).2005. p. 231-46.

. Is counseling a feminist practice? Estados Unidos: Geojournal. Vol. 65(4), 2006. 339-48.

CARLOS, Ana Fani Alessandri. O lugar no/do mundo. $1^{\circ}$ ed. São Paulo: Labur Edições, 2007.

Da "Organização" à "produção" do espaço no movimento do pensamento geográfico. In: A produção do espaço urbano: agentes e processos, escalas e desafios. CARLOS, Ana Fani; SOUZA, Marcelo Lopes de; SPOSITO, Maria Encarnação Beltrão (orgs.). São Paulo: Editora Contexto, 2011. p. 53-74.

CALLARD, F. 2003. The taming of psychoanalysis in geography. Social and Cultural Geography , 4(3), 295-312.

Consulting Rooms: Notes Towards a Historical Geography of the Psychoanalytic Setting. KINGSBURY, Paul; PILE, Steve (org). Estados Unidos: Ashgate Publishing Limited. 2014. p. 143-159 (online).

CORREAA, Roberto Lobato. Diferenciação sócio-espacial, escala e práticas espaciais. cidades, v. 4, n. 6, 2007, p. 62-72.

COVERLEY, Merlin. Psycogeography. Harpenden: Pocket Essentials.2006. p. 158

DAVIDSON, J.. Phobic Geographies: The Phenomenology and Spatiality of Identity Aldershot: Ashgate. 2003.

DAVIDSON, J., BONDI, L. and SMITH, M. Emotional Geographies . Aldershot: Ashgate. 2005

DAVIDSON, Joyce; PARR, Hester. Geographies of Psychic Life. In: Psycoanalytic Geographies, KINGSBURY, Paul; PILE, Steve (org). Estados Unidos: Ashgate Publishing Limited. 2014. p. 143-159 (online).

FREUD, S. Artigos sobre a técnica. A dinâmica da transferência. In S. Freud, Edição standard brasileira das obras psicológicas completas. Rio de Janeiro: Imago. (Trabalho original publicado em 1912)

O ego e o id. ESB, Rio de Janeiro: Imago, 1980 v. XIX. (Trabalho original publicado em 1927)

GUIMARAES, Leandro Buzzo Mourão; Luz. Construção do Lugar geográfico de alunos com transtorno do espectro Autismo em instituições públicas de ensino: contribuições da psicanálise. Revista Geografia em Atos. Edição Especial. Vol 2. N.2. 2015

GUIMARÃES, Raul Borges. Regionalização da saúde no Brasil: da escala do corpo à escala da nação. São Paulo, Universidade de São Paulo, Faculdade de Saúde Pública, 2008. (Tese de Livre Docência) 
KINGSBURY, P. Psychoanalytic approaches, in A Companion to Cultural Geography, edited by J.S. Duncan, N.C. Johnson and R. Schein. Blackwell: Oxford, 2003. p. 108-20.

Psychoanalysis, in International Encyclopedia of Human $\overline{\text { Geography }}$, edited by R. Kitchin and N. Thrift. Oxford: Elsevier. 2009. p. 48086.

MELO, João Baptista Ferreira de . O triunfo do Lugar sobre o Espaço. In: MARANDOLA-JUNIOR, EDUARDO; HOLZER, Werther, OLIVEIRA, Lívia. Qual o Espaço do Lugar? Rio de Janeiro: Perspectiva,2012 pp. 33-68.

OLÍVEIRA, Lívia de. O sentido do Lugar. In: MARANDOLA-JUNIOR, EDUARDO; HOLZER, Werther, OLIVEIRA, Lívia. Qual o Espaço do Lugar? Rio de Janeiro: Perspectiva,2012 pp. 3-16.

SIBLEY, D. 2003. Psychogeographies of rural space and practices of exclusion. Country Visions, edited by P. Cloke. Prentice Hall: Harlow, 218-31.

SILVA, Armando Corrêa da. Geografia e lugar social. São Paulo: Ed. Contexto, 1991

A aparência, o Ser e a Forma - Geografia e Método. Niterói: Geografia. vol.2, ed.3. 2000. p.07-25.

SPOSITO, Maria Encarnação. Produção do Espaço urbano: escalas, diferenças e desigualdades socioespaciais. In: A produção do espaço urbano: agentes e processos, escalas e desafios. CARLOS, Ana Fani; SOUZA, Marcelo Lopes de; SPOSITO, Maria Encarnação Beltrão (orgs.). São Paulo: Editora Contexto, 2011. p. 53-74

MAZZOLINI, Beatriz Pinheiro Machado. Rabiscando para ser: do si mesmo para o papel. Revista imaginário (USP). Vol. vol. 13, 2007.p.493-50.

MCGEACHAN, Cheryl . "Worlding" Psychoanalytic Insights: Unpicking R.D. Laing's Geographies. In: Psycoanalytic Geographies, KINGSBURY, Paul; PILE, Steve. Estados Unidos: Ashgate Publishing Limited. 2014. p. 114-126 (online).

OLIVEIRA, A.A.S.; LEITE, L.P. Construção de um sistema educacional inclusivo: um desafio político-pedagógico. Revista Ensaio: Avaliação e Políticas Públicas em Educação. Vol. 15, fascículo 57, Cesgranrio/RJ, 2007.

RELPH, E. Reflexões sobre a Emergência, Aspectos e Essência do Lugar. In: MARANDOLA-JUNIOR, EDUARDO; HOLZER, Werther, OLIVEIRA, Lívia. Qual o Espaço do Lugar? Rio de Janeiro: Perspectiva,2012 pp. 17-33.

WINNICOTT, D. W. O ambiente e os processos de maturação. Porto Alegre, Artes Médicas, 1983.

Natureza humana. Rio de janeiro, Imago, 1990

A criança e seu mundo. Rio de Janeiro, LTC, 1982. 